\title{
Social desirability, anonymity, and Internet-based questionnaires
}

\author{
ADAM JOINSON \\ University of Glamorgan, Pontypridd, Wales
}

\begin{abstract}
It has been argued that behavior on the Internet differs from similar behavior in the "real world" (Joinson, 1998a). In the present study, participants completed measures of self-consciousness, social anxiety, self-esteem, and social desirability, using either the World-Wide Web (WWW) or pen and paper, and were assigned to either an anonymous or a nonanonymous condition. It was found that people reported lower social anxiety and social desirability and higher self-esteem when they were anonymous than when they were nonanonymous. Furthermore, participants also reported lower social anxiety and social desirability when they were using the Internet than when they were using paper-based methods. Contrast analyses supported the prediction that participants using the WWW anonymously would show the lowest levels of social desirability, whereas participants answering with pen and paper nonanonymously would score highest on the same measure. Implications for the use of the Internet for the collection of psychological data are discussed.
\end{abstract}

According to estimates (e.g., Bride, 1996), there are around 50 million people connected to the Internet, a figure that increases by approximately $100 \%$ a year (MIDS, 1996). This growth in use has alerted many psychologists to the possibilities the Internet provides to support both psychology teaching (Hansen \& Gladfelter, 1996; Joinson, 1998b) and psychological research (Krantz, Ballard, $\&$ Scher, 1997). It would seem that the Internet may provide a "new method to obtain subjects" (Krantz et al., 1997, p. 264).

For instance, Stern and Faber (1997) reported the use of a lost e-mail technique that replicates Milgram's lostletter methodology. They found that, rather than forwarding a message to the intended recipient, participants returned it to the sender. In a follow-up attitude survey, Stern and Faber found equivalent responses with e-mail, as compared with traditional poll measures. Similarly, Krantz et al. (1997) reported that World-Wide Web (WWW) and laboratory collection methods "are driven by the same psychological variables" (p. 264). The Internet may indeed, therefore, prove to be an unrivaled environment for the collection of psychological and survey data, using a nonstudent sample (Buchanan \& Smith, 1999).

However, if the Internet is to become a new laboratory for psychological research, any findings must be generalizable to behavior in the "real world." A note of caution in this respect comes from an established body of research on computer-mediated communication (CMC) that suggests that behavior in on-line environments differs sig-

The author thanks Jo Trivette for her help in the collection of data and two anonymous reviewers for their helpful comments on an earlier draft of this article. Correspondence concerning this article should be addressed to A. Joinson, School of Humanities and Social Science, University of Glamorgan, Pontypridd, Mid-Glamorgan, CF37 1DL Wales (e-mail: ajoinson@glam.ac.uk). nificantly from equivalent behaviors in real life (Joinson, 1998a; Kiesler, Siegal, \& McGuire, 1984). A key behavioral difference between on line and real life is that users of computer networks can be characterized as disinhibited (Joinson, 1998a; Kiesler et al., 1984). That is, people on the Internet are more willing than they would be in real life to exchange hostilities (Kiesler et al., 1984), swap personal information (Parks \& Floyd, 1996), seek potentially threatening information (Joinson \& Harris, 1995), and publish normally protected aspects of themselves (see Joinson, 1998a, for a review). Disinhibited on-line behavior has been variously explained by deindividuation among computer users (Kiesler et al., 1984), reduced social presence (Short, Williams, \& Christie, 1976), reduced social cues during CMC (Kiesler et al., 1984), the activation of social identities (Reicher, Spears, \& Postmes, 1995), the reduction of public self-awareness aligned with an increase in private self-awareness (Matheson \& Zanna, 1988), and an interaction between context-dependent changes in public self-awareness and increased private self-awareness (Joinson, 1998a).

If the disinhibition noted among CMC users is also evident during the completion of questionnaires on the WWW, the explanation for such disinhibition becomes vitally important. If individuals are deindividuated while on line (Kiesler et al., 1984), then, according to deindividuation theory, their behavior will be characterized by increased hostility and reduced self-regulation (Zimbardo, 1969). Zimbardo rrgues that factors such as anonymity, arousal, sensory overload, and a reduction in self-focus lead to deindividuation and, thence, to disinhibited, hostile behavior.

In a reformulation of deindividuation theory, PrenticeDunn and Rogers (1982) suggest that deindividuation is caused by two factors - a reduction in accountability cues (e.g., anonymity leading to a reduced concern about oth- 
ers' reactions) and a reduction in private self-awarenesswhich lead to decreased self-regulation and use of internal standards. Kiesler et al. (1984) argue that the combination of anonymity, task focus, and reduced social cues may make computer users deindividuated. If the same applies to the completion of Internet-based questionnaires, the anonymity usually assumed to reduce social desirability and lead to more "honest" answers would lead to answers associated with a deindividuated state - that is, responses characterized by increased hostility, increased aggression, and reduced self-regulation.

However, the explanations of disinhibited CMC behavior proposed by Lea and Spears (1991) and Matheson and Zanna (1988) suggest that computer use encourages self-focus; so, people's behavior on line is more closely regulated than similar behavior in real life (Carver \& Scheier, 1981). Matheson and Zanna present evidence to suggest that, during $\mathrm{CMC}$, people experience increased private self-awareness (which could explain greater selfdisclosure), while simultaneously experiencing reduced public self-awareness (hence, less concern for others' opinions). This would suggest that, although selfpresentation concerns are reduced (via lower public selfawareness), self-regulation and focus on internal states and standards may be enhanced (via higher private selfawareness). This explanation differs significantly from earlier deindividuation explanations in that it essentially argues that people are being their "real" selves during CMC (although Reicher et al., 1995, argue that it is a social, not a personal, identity that is activated). If this explanation were true, it would suggest that the Internet is indeed a useful laboratory for psychological research. Reduced public self-awareness should lead to reduced selfpresentation concerns and, therefore, to less need for social desirability (Crowne \& Marlowe, 1960). Indeed, there is some evidence that self-disclosure of personal information is higher during computerized testing (Greist, Klein, \& Van Cura, 1973; Locke \& Gilbert, 1995).

The research in this paper examines the effect of using the Internet on measures of self-consciousness, social anxiety, self-esteem, and social desirability. Because any effect may be due to the Internet's being perceived by participants as more anonymous than pen-and-paper tests, a second variable, level of anonymity, is incorporated into the design.

It is predicted that, when completing questionnaires on the Internet, as compared with pen and paper, participants will show lower social desirability and social anxiety responses. Because self-consciousness is normally seen as a fixed trait rather than as malleable (Fenigstein, Scheier, \& Buss, 1975), it should not be affected by whether the questionnaire is answered on the WWW or with pen and paper. Self-esteem scores are predicted to differ according to the medium used, but the direction in which it will differ is not predicted. Being freed from presentation concerns could release participants from the need for false modesty, or it may allow them to portray themselves in a more negative light.

It is also predicted that participants will show higher social desirability and higher social anxiety when they are nonanonymous than when they are anonymous. Again, self-consciousness is not predicted to differ, whereas the predicted difference in self-esteem is again two-tailed. It is further predicted that the lowest scores on social desirability and social anxiety scales will be found with Internet use and anonymity, and the highest will be found with a paper-and-pencil tests and nonanonymity.

\section{METHOD}

\section{Design}

A $2 \times 2$ between-subjects factorial design was used. The independent variables were the form of the questionnaire (WWW vs. paper) and the anonymity status of the participants (anonymous vs. nonanonymous). The participants' scores on the measures formed the dependent variables.

\section{Participants}

The participants were 82 students enrolled in an introductory research methods course at the University of Glamorgan. Mean age of the participants was 22.22 years $(S D=5.92)$, with 43 females included in the sample. The mean age of participants using the WWW ( $n=41,20$ females) to answer the questionnaires was 22.89 years $(S D=5.91)$. The mean age of participants using pen and paper $(n=41,23$ females $)$ was 20.95 years $(S D=3.07)$.

\section{Materials}

Self-consciousness. The measure of self-consciousness used was developed by Fenigstein et al. (1975). This scale has three subscales: public self-consciousness (e.g., "I'm concerned about what other people think of me"; factor loading, .73), private self-consciousness (e.g., "I reflect about myself a lot"; factor loading, .73), and social anxiety (e.g., "It takes me time to overcome my shyness in new situations"; factor loading, .76). Each item was answered with a 4-point Likert scale anchored at strongly disagree, disagree, agree, and strongly agree.

Self-esteem. The participants also completed the Rosenberg Self-Esteem Scale (Rosenberg, 1979). This scale is a trait measure of self-esteem comprising 10 items (e.g., "I feel that I have a number of good qualities"). This scale was answered with the same Likert scale as that described above.

Social desirability. The Balanced Inventory of Responding Bias (BIDR) (Paulhus, 1991) was used to measure social desirability. The items in the BIDR (e.g., "I am not a safe driver when I exceed the speed limit" [reverse scored] and "I never cover up my mistakes") were answered with the same Likert scale as that for the other measures.

The layout of the questionnaires was the same across conditions; the paper version was a printout of the WWW-based version. In the nonanonymous condition, an extra box was added at the top of the questionnaire that asked for the participants' names.

\section{Procedure}

The participants in the WWW condition were approached by the experimenter during a research methods class in a computer laboratory. If they agreed to participate in the study, they were handed a brief instruction sheet giving the WWW address of the questionnaire and thanking them for their help. All the participants in the WWW condition completed the questionnaires immediately after 


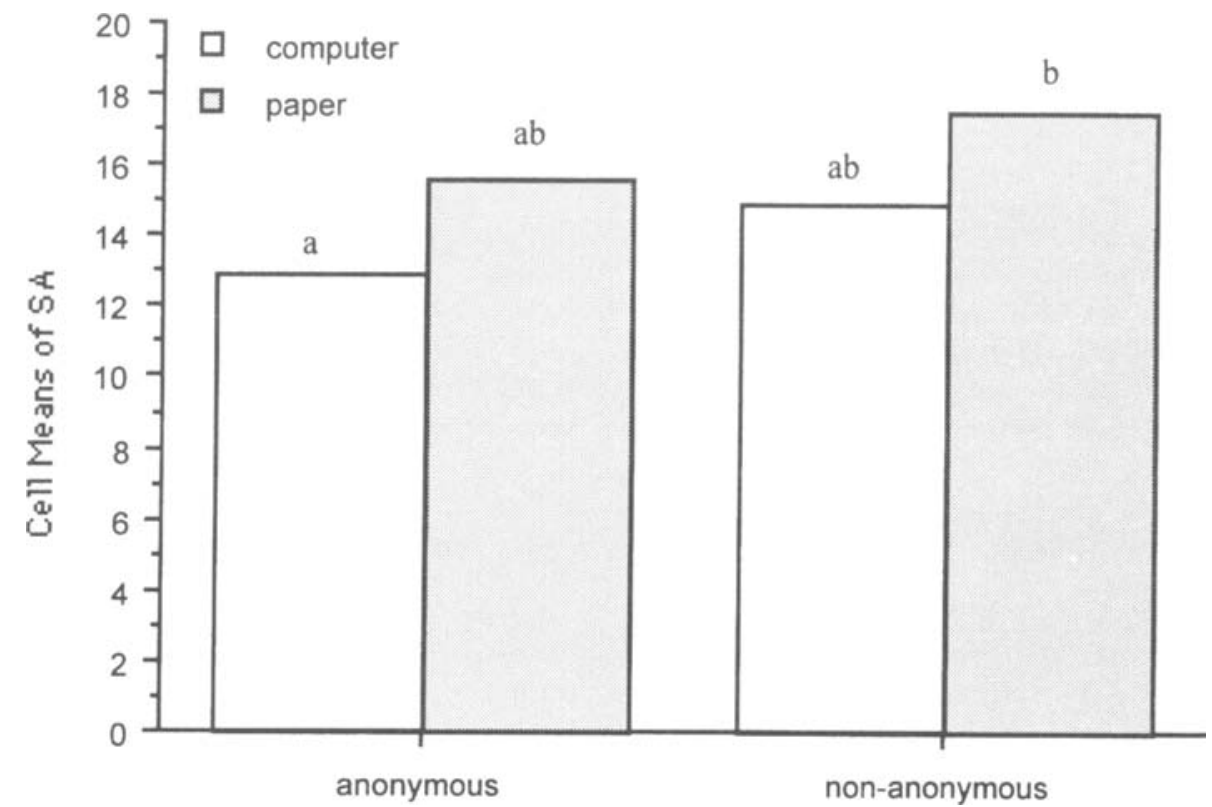

Figure 1. Cell means for social anxiety (SA) across conditions. Columns sharing a letter do not differ significantly ( $5 \%$ Scheffé).

recruitment and after being handed the instruction sheet. The participants were tested in a group setting, with each student answering the questions on separate PCs spaced approximately $1 \mathrm{~m}$ apart. The top of the WWW questionnaire read, "Please answer each item using the scale provided below. ... Once you have answered each item please press the submit button at the end of the file." The experimenter was present during the testing.

The participants in the pen-and-paper condition were similarly handed an instruction sheet during class and asked to complete the questionnaire by following the same instructions, with the reference to a submit button having been removed. To ensure that the independent variable (WWW vs. paper) was not transparent to the participants, the paper and WWW conditions were run separately in different lab classes. That is, two classes made up the WWW condition, and two further classes made up the pen-and-paper condition.

The participants were assigned to the anonymous or the nonanonymous condition, using randomly assorted instruction sheets (giving differing addresses for the WWW questionnaires or fronting different questionnaire packs when on paper). In the anonymous condition, the participants' instructions included the phrase, in bold type, that "all your answers are anonymous and cannot be linked to you." In the nonanonymous condition, this information was removed and replaced with an instruction to "make sure you put your name in the box." After completion of the questionnaires, all the participants were thanked for their time and debriefed.

\section{RESULTS}

A series of two-way, between-subjects analyses of variance were calculated, to examine the main effects of Internet versus paper responses and of anonymous versus nonanonymous responses and to check for any interaction between form of questionnaire and level of anonymity. Cohen's $d$ was used as a measure of effect size (Cohen, 1977).

As was predicted, private self-consciousness showed no main effects $[F \mathrm{~s}(1,78) \leq 0.62, p \mathrm{~s} \geq .43]$ for either form of questionnaire $(M \mathrm{~s}=29.75$ and 29.92 for WWW and paper, respectively) or level of anonymity $(M s=29.67$ and 30.02 for anonymous and nonanonymous, respectively). Similarly, the public self-consciousness measure showed no main effects $[F \mathrm{~s}(1,78) \leq 3, p \mathrm{~s} \geq .09]$ for either form of questionnaire $(M \mathrm{~s}=18.73$ and 17.76 for WWW and paper, respectively) or level of anonymity $(M \mathrm{~s}=18.13$ and 18.33 for anonymous and nonanonymous, respectively).

The social anxiety measure showed main effects of form of questionnaire $[F(1,78)=15.01, p<.001, d=.84 ; M \mathrm{~s}=$ 13.93 and 16.62 for Internet and paper, respectively] and level of anonymity $[F(1,78)=7.72, p<.01, d=.59 ; M \mathrm{~s}=$ 14.30 and 16.26 for anonymous and nonanonymous, respectively] but no interaction $[F(1,78)=0.05, p=.94$; see Figure 1].

The self-esteem measure showed a marginally significant main effect of form of questionnaire $[F(1,78)=3.26$, $p=.07, d=.39 ; M \mathrm{~s}=31.43$ and 29.45 for Internet and paper, respectively] and a significant effect of level of anonymity $[F(1,78)=23.25, p<.001, d=1.06 ; M \mathrm{~s}=$ 32.95 and 28.00 for anonymous and nonanonymous, respectively] but, again, no significant interaction $[F(1,78)=$ $1.72, p=.19$; see Figure 2].

The social desirability measure (BIDR) showed main effects of form of questionnaire $[F(1,78)=67.43, p<.001$, $d=1.72 ; M \mathrm{~s}=81.55$ and 94.74 for Internet and paper, respectively $]$ and level of anonymity $[F(1,78)=13.93, p<$ $.01, d=.65 ; M \mathrm{~s}=85.10$ and 91.36 for anonymous and nonanonymous, respectively] but no interaction $[F(1,78)=$ $0.69, p=.40$; see Figure 3).

To test the final prediction, that the lowest scores on the social desirability and social anxiety scales will be when 


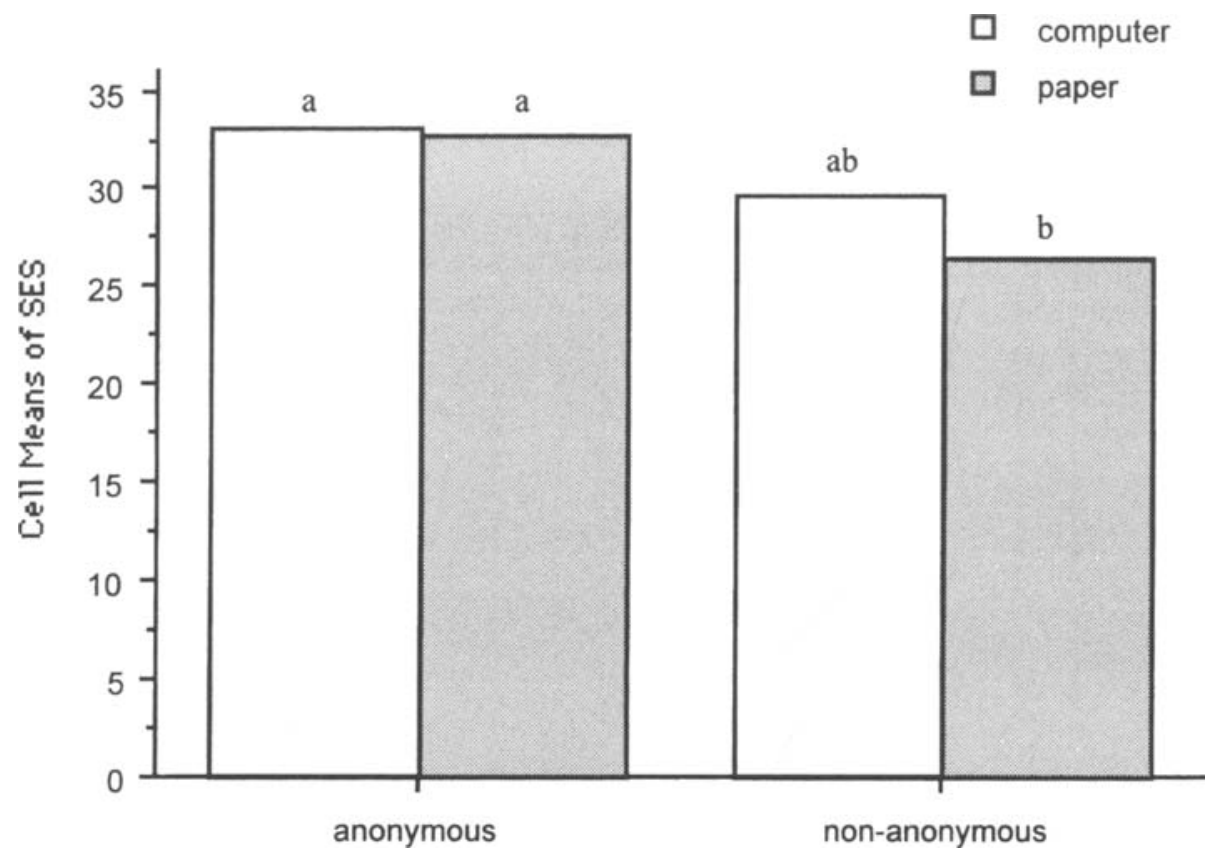

Figure 2. Cell means for self-esteem (SES) across conditions. Columns sharing a letter do not differ significantly ( $5 \%$ Scheffé).

using the Internet and anonymous and the highest will be when using the paper-and-pencil test and nonanonymous, contrast analyses were calculated (Rosenthal \& Rosnow, $1985)$. For both analyses, the Internet use while anonymous condition was given a lambda $(\lambda)$ weighting of 1 , and the paper-and-pencil test while nonanonymous condition was given a weighting of -1 . The remaining two con- ditions were weighted at zero. The contrast analyses confirmed a significant difference for both social desirability scores $[F(1,78)=73.02, p<.001$; means for WWW/ anonymous and paper/nonanonymous are 79.25 and 98.18 , respectively] and social anxiety scores $[F(1,78)=$ $22.65, p<.001$; means for WWW/anonymous and paper/ nonanonymous are 12.95 and 17.50 , respectively].

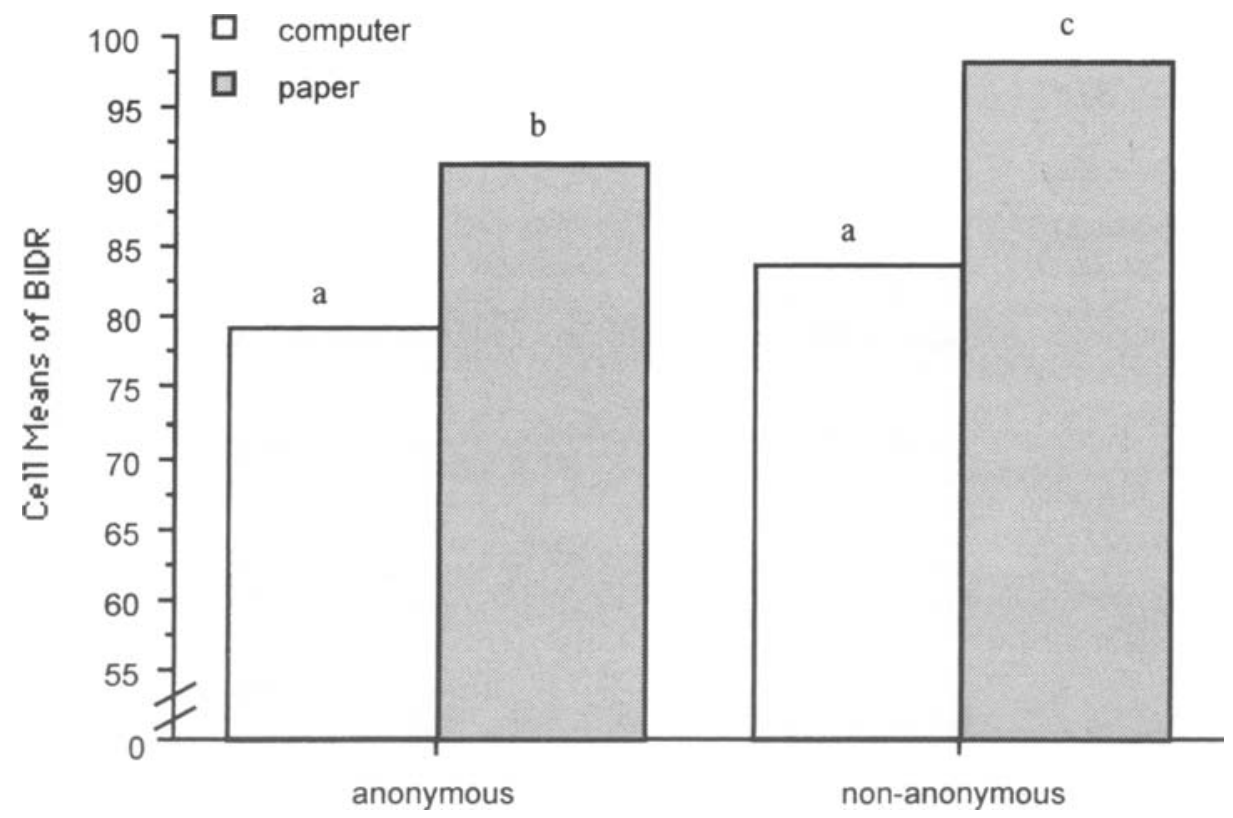

Figure 3. Cell means for social desirability (BIDR) across conditions. Columns sharing a letter do not differ significantly (5\% Scheffé). 


\section{DISCUSSION}

In this experiment, the participants using the WWW to complete self-relevant questionnaires responded in a significantly different way, as compared with the participants completing the questionnaires with pen and paper. Specifically, the participants using the WWW scored significantly lower on measures of social desirability and social anxiety and scored marginally higher on a measure of self-esteem than did the participants completing the questionnaires with pen and paper.

Moreover, the anonymous participants scored significantly lower on measures of social anxiety and social desirability and significantly higher on the measure of selfesteem. The pattern and direction of these results (with the exception of the two-tailed self-esteem hypotheses) support the experimental hypotheses. Thus, evidence of disinhibition (lower social desirability and social anxiety scores) was seen when the participants were using the WWW and when they were anonymous. As was predicted, the combination of WWW completion of the measures and anonymity produced the lowest social desirability and social anxiety scores, whereas the nonanonymous participants using pen and paper scored highest on social desirability and social anxiety. The significance of this difference was confirmed by the results of the contrast analyses.

The findings reported in this paper lend some support to the explanation of disinhibited on-line behavior proposed by Matheson and Zanna (1988). Matheson and Zanna argued that disinhibition during $C M C$ is caused by increased private self-awareness and decreased public selfawareness. In the present research, since the questionnaires were self-relevant, it would be expected that all the participants were privately self-aware (after all, such questionnaires are effectively asking the participants to introspect). The highest levels of disinhibition (taken as low social desirability and low social anxiety scores) were when the participants completed measures on the WWW anonymously. Because anonymity is usually argued to decrease evaluation concerns (Prentice-Dunn \& Rogers, 1982), whereas using computers is argued to increase self-regulation on the basis of internal standards (Joinson, 1998a), it could be argued that the participants in this condition experienced low public self-awareness, accompanied by high private self-awareness.

In the present research, the interaction between level of anonymity and medium on social desirability scores was not significant. This suggests that the main effect of anonymity applied equally across both the pen-and-paper and the WWW participants. However, the subsequent post hoc tests suggest that being nonanonymous, as opposed to anonymous, had only a small effect on social desirability scores for the WWW participants (see Figure 3). This may be because the effect of using the WWW on reducing public self-awareness is strong enough to ameliorate the impact of nonanonymity. Alternatively, the nonanonymity manipulation for the WWW participants may not have been strong enough. For instance, the nonanonymous participants using the WWW may have forgotten their nonanonymous status because the name place was scrolled out of view. A further possibility is that sending answers into the "ether" of the Internet may lead participants to separate their nonanonymity from the receipt of the questionnaire and its being linked to them.

The role of perceived anonymity is an important one. Most Internet research does not recruit participants in the laboratory but, rather, through postings in newsgroups or search engine advertisements. In the present research, the need to compare the WWW and pen-and-paper samples required that students in a computer laboratory should complete the WWW-based version of the measures. However, this does introduce potential problems with the applicability of the findings to Internet samples per se. It would be expected that the perception of anonymity might be greater among genuinely Internet-based participants, suggesting that the results reported here might underestimate any disinhibition in on-line questionnaire completion. Finally, if the WWW is perceived as anonymous, even by nonanonymous participants, the differences between the WWW and the pen-and-paper participants found in the present study could be interpreted as partial support for the deindividuation explanation of on-line behavior (Kiesler et al., 1984). That is, the main effect of medium (WWW vs. paper) could be due to differences in perceived anonymity and, thus, accountability cues (Prentice-Dunn \& Rogers, 1982), rather than to the effect of the WWW condition on self-awareness.

To address the question of perceived anonymity, it may be worth asking participants to complete a series of questionnaires on line and then print it out and hand it to the experimenter. This would ensure that the process of using the computer and nonanonymity are separated. A further point, worthy of future consideration, is that individual differences may interact with any WWW versus paper effect, particularly with regard to participants' scores on the measure of social desirability. Potential individual differences that might interact with a WWW/ paper effect include participants' levels of need for approval, self-monitoring, and trait self-consciousness. If completion of WWW-based questionnaires is characterized by low public self-awareness and high private selfawareness among participants, the behavior of individuals who are more concerned with public image than with private ideals might be more affected when using the $\mathrm{WWW}$, as compared with the behavior of individuals who value consistency between their inner beliefs and their public persona. Undoubtedly', a concerted program of research is urgently required to identify any interaction between individual differences and responses to on-line experiments.

In view of the well-established body of research suggesting that on-line life is characterized by disinhibited behavior (see Joinson, 1998a), it would be surprising if similar levels of disinhibition were not evident during the completion of psychological measures on line. Differences in on-line and pen-and-paper responses have implications for psychologists planning to use the Internet to collect 
data. First, it is unclear whether personality measures would be answered differently on line than with more traditional methods. I would suggest that researchers take care to compare their Internet-derived data with established population means and consider the psychometric properties of on-line measures, as compared with their pen-and-paper counterparts (see Buchanan \& Smith, 1999). Second, in the present research, no significant differences were found in trait measures (e.g., selfconsciousness), so the Internet may be more suited to measures of stable attributes. Finally, if social desirability is consistently found to be lower on the Internet than with pen-and-paper tests, the Internet may prove to be a more accurate sampling method than traditional techniques.

The argument that WWW and laboratory collection methods "are driven by the same psychological variables" (Krantz et al., 1997, p. 264) is not questioned by the findings of the present experiment. The relationships between psychological variables are likely to be equivalent across media, but the mean scores for some measures may be different. This is, of course, not necessarily a problem. Indeed, participants completing psychological measures, especially self-relevant ones, might respond more honestly on line than on paper. However, researchers should be aware of the potential differences between on-line and traditional data collection methods.

\section{REFERENCES}

BRIDE, M. (1996). Teach yourself the Internet. London: Hodder Headline.

Buchanan, T., \& SMiTh, J. L. (1999). Using the Internet for psychological research: Personality testing on the World-Wide Web. British Journal of Psychology, 90, 125-144.

CARVer, C. S., \& SCHEIER, M. F. (1981). Attention and self-regulation: $A$ control theory approach to human behavior. New York: SpringerVerlag.

COHEN, J. (1977). Statistical power analysis for the behavioral sciences (Rev. ed.). New York: Academic Press.

Crowne, D. P., \& Marlowe, D. (1960). A new scale of social desirability independent of psychopathology. Journal of Consulting Psychology, 24, 349-354.

Fenigstein, A., Scheier, M. F., \& Buss, A. H. (1975). Public and private self-consciousness: Assessment and theory. Journal of Consulting \& Clinical Psychology, 43, 522-527.

Greist, J. H., KLein, M. H., \& VAN CURA, L. J. (1973). A computer interview by psychiatric patient target symptoms. Archives of General Psychiatry, 29, 247-253.

Hansen, N. E., \& GladFelter, J. (1996). Teaching graduate psychology seminars using electronic mail: Creative distance education. Teaching of Psychology, 23, 252-256.

Joinson, A. N. (1998a). Causes and implications of disinhibited behavior on the Net. In J. Gackenbach (Ed.), Psychology of the Internet (pp. 43-60). New York: Academic Press.
Jornson, A. N. (1998b). Social psychological applications of educational simulation. In J. Rolfe, D. Saunders, \& T. Powell (Eds.), Simulation and gaming research yearbook (Vol. 6, pp. 155-160). London: Kogan Page.

JoInson, A. N., \& HARRIS, P. R. (1995). Self-enhancement and selfprotection on the Internet: A study of football fans on the WWW. Paper presented at the BPS London Conference, Institute of Education, London.

Kiesler, S., Siegal, J., \& McGuire, T. W. (1984). Social psychological aspects of computer mediated communication. American Psychologist, 39, 1123-1134.

Krantz, J. H., Ballard, J., \& SCher, J. (1997). Comparing the results of laboratory and World-Wide Web samples on the determinants of female attractiveness. Behavior Research Methods, Instruments, \& Computers, 29, 264-269.

LEA, M., \& SPEARS, R. (1991). Computer-mediated communication, deindividuation and group decision making. International Journal of Man-Machine Studies, 39, 283-301.

Locke, S. D., \& Gilbert, B. O. (1995). Method of psychological assessment, self-disclosure, and experimental differences: A study of computer, questionnaire and interview assessment formats. Journal of Social Behavior \& Personality, 10, 255-263.

Matheson, K., \& ZanNa, M. P. (1988). The impact of computermediated communication on self-awareness. Computers in Human Behavior, 4, 221-233.

MIDS (1996). Matrix Information and Directory Services 3rd Internet Survey. Downloaded June 1997 from http://www3.mids.org/mn/601/ demo9510.html

Parks, M. R., \& Floyd, K. (1996). Making friends in Cyberspace. Journal of Computer-Mediated Communication, 1. Downloaded June 1997 from http://jmc.huji.ac.il/vol 1/issue4/parks.html

Paulhus, D. L. (1991). Measurement and control of response bias. In J. P. Robinson, P. R. Shaver, \& L. S. Wrightsman (Eds.), Measures of personality and social psychological attitudes (pp. 17-59). New York: Academic Press.

Prentice-Dunn, S., \& Rogers, R. W. (1982). Effects of public and private self-awareness on deindividuation and aggression. Journal of Personality \& Social Psychology, 43, 503-513.

Reicher, S. D., Spears, R., \& Postmes, T. (1995). A social identity model of deindividuation phenomena. In W. Stroebe \& M. Hewstone (Eds.), European review of social psychology (Vol. 6, pp. 161-198). Chichester, U.K.: Wiley.

Rosenberg, M. (1979). Conceiving the self. New York: Basic Books. Rosenthal, R., \& Rosnow, R. L. (1985). Contrast analysis: Focused comparisons in the analysis of variance. Cambridge: Cambridge University Press.

Short, J. A., Williams, E., \& Christie, B. (1976). The social psychology of telecommunication. Chichester, U.K.: Wiley.

STERN, S. E., \& FABER, J. E. (1997). The lost e-mail method: Milgram's lost-letter technique in the age of the Internet. Behavior Research Methods, Instruments, \& Computers, 29, 260-263.

ZIMBARDO, P. G. (1969). The human choice: Individuation, reason, and order vs. deindividuation, impulse and chaos. In W. J. Arnold \& D. Levine (Eds.), Nebraska symposium on motivation (pp. 237-307). Lincoln: University of Nebraska Press.

(Manuscript received May 19, 1998; revision accepted for publication January 7,1999 .) 